\author{
Д.В. Сергеев ${ }^{1}$, М.А. Пирадов ${ }^{1}$, М.Ю. Максимова ${ }^{1}$, М.А. Домашенко ${ }^{1}$, \\ А.Н. Сергеева ${ }^{1}$, Ф.Р. Охтова ${ }^{2}$ \\ ${ }^{1}$ Научный центр неврологии РАМН, \\ ${ }^{2}$ Московский государственный медицинский стоматологический университет
}

\title{
Новые возможности нейропротекции при ишемическом инсульте
}

\begin{abstract}
Реперфузия и нейропротекция - два современных стратегических направления терапии пациентов с острым инсультом. С позиций медицины, основанной на доказательствах, представлен обзор современных препаратов, применяемых с иелью нейропротекции при ишемических острых нарушениях мозгового кровообращения.
\end{abstract}

Ключевые слова: инсульт, нейропротекция.

Контакты: Максим Алексеевич Домашенко mdomashenko@gmail.com

New possibilities of neuroprotection in ischemic stroke

D.V. Sergeyev ${ }^{1}$, M.A. Piradov ${ }^{1}$, M.Yu. Maksimova ${ }^{1}$, M.A. Domashenko ${ }^{1}$, A.N. Sergeyeva ${ }^{1}$, F.R. Okhtova ${ }^{2}$

${ }^{I}$ Neurology Research Center, Russian Academy of Medical Sciences, ${ }^{2}$ Moscow University of Medicine and Dentistry

Reperfusion and neuroprotection are two present-day therapy strategies for patients with acute stroke. The paper reviews currently available drugs used for neuroprotection in ischemic strokes in the context of evidence-based medicine.

Key words: stroke, neuroprotection.

Contact: Maksim Alekseyevich Domashenko mdomashenko@gmail.com

На протяжении многих лет острые нарушения мозгового кровообращения являются объектом пристального изучения неврологов, кардиологов, нейро- и ангиохирургов, врачей лучевой диагностики и специалистов по реабилитации. Причина такого интереса - огромное социальное значение этих заболеваний, вследствие которых ежегодно в мире погибают около 5 млн человек и еще около 5 млн становятся инвалидами. Программы по борьбе с его инсультом и его активная профилактика дают отчетливый эффект: за последние 40 лет в странах с высоким уровнем доходов по классификации ВО3 заболеваемость инсультом снизалась на $42 \%$, а смертность от него уменьшается на $1,1 \%$ в год [1].

Сегодня единственным методом лечения наиболее распространенного типа острого нарушения мозгового кровообращения - ишемического инсульта (ИИ) является тромболитическая терапия (стратегия восстановления проходимости церебральных сосудов), эффективность которой доказана в плацебоконтролируемых исследованиях. Применение алтеплазы (рекомбинантного тканевого активатора плазминогена) у отобранных надлежащим образом пациентов улучшает исход инсульта (восстановление повседневной активности через 90 дней) по сравнению с плацебо [2-6]. Однако реальная возможность проведения тромболизиса доступна лишь 5-10\% пациентов, в связи с этим продолжается разработка альтернативного направления терапии ИИ - нейропротекции. Под нейропротекцией подразумевается любая стратегия лечения (как монотерапия, так и комбинированное лечение), которая препят- ствует, прерывает или замедляет последовательность повреждающих биохимических и молекулярных процессов, способных вызвать необратимое ишемическое повреждение головного мозга [7].

\section{Основные тенденции разработки}

нейропротективных препаратов

За последние 20 лет на исследование и разработку средств для лечения инсульта было затрачено около 1 млрд долларов, однако достигнутые результаты несопоставимы с этими огромными вложениями [8]. Определенную надежду на успех вселяют экспериментальные исследования, которые позволили получить неоспоримые доказательства того, что с помощью ранней нейропротекции можно добиться восстановления до $80 \%$ объема ишемизированной ткани. В связи с этим количество исследований в области нейропротекции увеличивается с каждым годом: с 2001 по 2007 г. появилось около 1000 экспериментальных и более 400 клинических работ [7]. Были выявлены различные механизмы повреждения нервной ткани при ишемии и установлены мишени для терапевтического вмешательства: практически каждый элемент патофизиологического каскада является точкой приложения того или иного нейропротективного агента.

Тем не менее препараты, показавшие хорошие результаты в экспериментах на животных, не продемонстрировали убедительную клиническую эффективность [7]. Разработка более 1000 активных веществ была прекращена на той или иной стадии в связи с отсутствием положительных результатов [9]. Ни у одного из препаратов, эффективных по 
крайней мере у некоторых подгрупп пациентов (например, цитиколин, пирацетам, клометиазол) или в исследованиях 2-й фазы, не установлена клиническая эффективность в крупных исследованиях 3-й фазы [10, 11]. Ярким примером этого может служить акцептор свободных радикалов NXY059: возлагавшиеся на него большие надежды основывались на позитивных результатах исследования SAINT I, проведенного у 1722 пациентов [12]. Однако эти результаты не подтвердились в дальнейшем в более масштабном исследовании 3-й фазы SAINT II [13, 14 ].

Неудачи исследований нейропротективных препаратов в клинических условиях в основном были связаны с тем, что модели церебральной ишемии у животных, на которых изучали эффективность препаратов, не в полной мере отражают условия формирования инфаркта головного мозга у человека. Последний является в значительной степени более гетерогенным, чем воспроизведенные в стандартизированных лабораторных условиях модели ишемии. Основные претензии к экспериментальным исследованиям включали в себя использование препаратов у человека в недостаточно эффективной дозе или вне соответствующего «временного окна», несовершенство методик прекращения кровоснабжения ткани мозга у животных (временная или постоянная окклюзия средней мозговой артерии), а также использование в доклинических исследованиях молодых здоровых животных, в то время как большинство пациентов с инсультом - пожилые люди, страдающие такими сопутствующими заболеваниями, как артериальная гипертензия, сахарный диабет, инфаркт миокарда и т. д., которые могут влиять на структуру гематоэнцефалического барьера, коллатеральное кровообращение или нейроиммунную систему. Под сомнение ставилась также адекватность размера выборки и дизайна доклинических исследований. В конце 1990-х гг. группой ученых совместно с представитями фармацевтической промышленности были предложены рекомендации по доклинической разработке нейропротективных препаратов [15-17], направленные на устранение указанных недостатков (критерии STAIR). При анализе 912 препаратов, изучавшихся на доклиническом этапе, и 14 препаратов, исследовавшихся у человека, оказалось, что эффективность средств, дошедших до стадии клинических исследований, и препаратов, разработка которых прекратилась еще в лабораторных условиях, в целом не отличалась [9]. Исследования только 4 препаратов/вмешательств были проведены в соответствии со всеми 10 критериями STAIR: к ним относились исследования гипотермии, NXY059, антагониста NMDA-рецепторов ARL15896 и основного фактора роста фибробластов. В итоге в клинических условиях нейропротективные свойства были доказаны только для гипотермии после остановки сердца [18]. Вероятно, чтобы добиться успеха на клиническом этапе разработки потребуется внедрение критериев STAIR (2010 г.) для клинических исследований 2-й и 3-й фазы [17]. В то же время отмечается, что с момента опубликования отрицательных результатов исследования SAINT II и внедрения требований STAIR так и не произошло сколько-нибудь значимого улучшения качества доклинических исследований нейропротективных препаратов [11].

Остановимся подробнее на наиболее важных для клинической практики препаратах и вмешательствах, оказывающих нейропротективное действие.

\section{Н и м оди п и н}

Ион кальция играет центральную роль в ишемическом повреждении церебральной ткани. Блокатор кальциевых каналов нимодипин обладает эффектом в отношении нейронов, препятствуя входу кальция в клетку, а также вызывает расширение церебральных сосудов. В 5 наиболее крупных клинических исследованиях нимодипина при приеме внутрь и внутривенном введении участвовало около 3400 пациентов, а в метаанализе, проведенном Кохрановским сообществом, исследовались данные 7500 пациентов. Во всех исследованиях и метаанализе получены отрицательные результаты [3]. Основной проблемой в этих исследованиях было позднее начало терапии (спустя 24-48 ч после начала инсульта). В ряде исследований объем выборки был слишком мал, чтобы продемонстрировать эффект лечения.

\section{М аг ний}

Магний рассматривается как эндогенный антагонист кальция, нейропротективный эффект которого связан с рядом механизмов: блокадой NMDA-рецепторов, ингибированием высвобождения эксайтотоксических медиаторов, блокированием кальциевых каналов, а также расслаблением гладкой мускулатуры [19]. Сульфат магния изучался в крупном многоцентровом исследовании IMAGES у пациентов с острым инсультом в течение 12 ч после его развития. Эффективность препарата, которая оценивалась по частоте инвалидизации, не доказана; смертность в группе сульфата магния была несколько выше, чем в группе плацебо [20].

В настоящее время продолжается исследование сульфата магния 3-й фазы, в котором препарат рассматривается в качестве прототипа нейропротективного средства для терапии острейшего инсульта, начатой до госпитализации пациента, и проведения нейровизуализации в течение первых 2 ч после начала заболевания [21].

\section{П ирацета м}

Пирацетам - препарат, влияющий на текучесть мембран, обладающий нейропротективными и противосудорожными свойствами [22, 23]. В исследовании 3-й фазы при применении пирацетама в течение 12 ч после развития заболевания в дозе 12 г внутривенно и затем в дозе 12 г/сут в течение 4 нед не выявлено его преимуществ по сравнению с плацебо [24].

\section{Э тилметилгидроксипиридина с сукцинат} ( н ейрок С)

Этилметилгидроксипиридина сукцинат (мексидол, нейрокс) представляет собой производное янтарной кислоты, которое оказывает антигипоксическое, мембранопротективное, ноотропное, противосудорожное, анксиолитическое действие. В ряде проведенных в нашей стране открытых исследований на небольших выборках пациентов в первые несколько суток после начала инсульта продемонстрированы безопасность и положительный эффект препарата в отношении уменьшения выраженности двигательного дефицита и восстановления повседневной активности, а также улучшения когнитивных функций $[25,26]$. В единственном на данный момент двойном слепом контролируемом исследовании у 51 пациента с острым ИИ в первые сутки заболевания при применении мексидола в дозе 300 мг/сут внутривенно в течение 14 сут отмечалось значимое уменьшение выраженности неврологического дефицита [27]. 


\section{Холина альфосцерат ( церетон}

Холина альфосцерат (церетон, глиатилин) оказывает нейропротективное действие благодаря увеличению синтеза ацетилхолина и участию в синтезе фосфатидилхолина, что улучшает синаптическую, в том числе холинергическую нейротрансмиссию. В трех неконтролируемых исследованиях у 2484 пациентов с инсультом и транзиторной ишемической атакой препарат улучшал функциональное восстановление [28]. Кроме того, в одном многоцентровом исследовании продемонстрировано положительное влияние холина альфосцерата на когнитивные функции [29]. Безопасность препарата и его эффект в отношении уменьшения выраженности двигательного дефицита у пациентов с ИИ в первые сутки заболевания отмечен в небольшом отечественном исследовании, в котором холина альфосцерат вводили внутривенно [2]. В другом российском пилотном открытом многоцентровом исследовании холина альфосцерата (глиатилин) при остром инсульте у 122 пациентов, получавших препарат, отмечались уменьшение неврологического дефицита и увеличение способности пациентов к самообслуживанию [30].

\section{цере бролизин}

Церебролизин - смесь пептидов с низкой молекулярной массой и свободных аминокислот, полученных из мозга свиней. Препарат оказывает плейотропное, а также нейропротективное, нейротрофическое и нейрорегенеративное действие, блокируя ряд элементов ишемического каскада [31]. Церебролизин в некоторых странах используется для лечения болезни Альцгеймера, а также травматического повреждения головного мозга. В доклинических исследованиях показано, что препарат уменьшает размер инфаркта и способствует восстановлению функций [32]. В многочисленных небольших клинических исследованиях с участием около 1500 пациентов с инсультом были продемонстрированы безопасность и хорошая переносимость препарата, в том числе улучшение двигательных и когнитивных функций и повседневной активности [33-35]. Тем не менее в Кохрановский обзор по применению церебролизина для лечения инсульта вошло всего одно контролируемое исследование, в котором не удалось продемонстрировать влияние церебролизина на восстановление повседневной активности после инсульта [36]. В завершившемся недавно крупном постмаркетинговом контролируемом исследовании, которое проводилось в 52 центрах в Азии и включало 1067 пациентов, у которых после развития инсульта прошло не более суток, также не удалось продемонстрировать эффективность церебролизина в отношении уменьшения выраженности неврологического дефицита и восстановления повседневной активности [37].

\section{Ц и т и коли и н}

Цитиколин (цитидин-5-дифосфохолин) - природный эндогенный мононуклеотид, участвующий в синтезе фософолипидов мембран клетки. Цитиколин оказывает антиоксидантный и мембраностабилизирующий эффект, ингибирует глутамат-индуцированный апоптоз и усиливет механизмы нейропластичности. В клинических исследованиях показана эффективность цитиколина в дозе 750-1000 мг/сут внутривенно на протяжении 10-14 дней у небольших групп пациентов с ИИ [38]. Дальнейшее подтверждение эффективности и безопасности цитиколина при ИИ проводилось в трех многоцентровых двойных сле- пых плацебоконтролируемых исследованиях [39-41]. Больные принимали препарат, начиная с первых суток заболевания, в дозе 500; 1000 и 2000 мг/сут на протяжении 6 нед. Значимые различия между группами цитиколина и плацебо в отношении восстановления неврологического дефицита и повседневной активности были выявлены только в первом исследовании [39]. В двух других исследованиях отмечалось улучшение исхода заболевания в подгруппах пациентов с умеренным и тяжелым инсультом.

В 2002 г. было проведено два метаанализа объединенных данных исследований цитиколина $[42,43]$. В первый из них были включены данные 1372 пациентов. Цитиколин применялся внутрь, начиная с первых суток заболевания, в дозе 500; 1000 и 2000 мг/сут. Полное восстановление достигнуто у $25,2 \%$ пациентов в группе цитиколина и у $20,2 \%$ в группе плацебо ( $\mathrm{p}=0,0043)$, причем наиболее эффективной оказалась терапия цитиколином в дозе 2000 мг (полное восстановление отмечалось у 27,9\% пациентов). Смертность и частота нежелательных явлений в группах цитиколина и плацебо не различались. Таким образом, лечение цитиколином, начатое в первые 24 ч после развития ИИ и проводившееся на протяжении 6 нед, улучшало вероятность полного восстановления через 3 мес у пациентов с умеренным и тяжелым неврологическим дефицитом [42].

Второй метаанализ был проведен Кохрановской группой и включал данные 7 исследований, объединивших 1963 пациентов, которые получали цитиколин в дозе от 500 до 2000 мг/сут [43]. Суммарный показатель смертности и инвалидизации в группе цитиколина был ниже, чем в группе плацебо (54,6 и 66,4\% соответственно, $\mathrm{p}<0,00001)$. При дальнейшем анализе с учетом данных только 4 наиболее крупных исследований были получены аналогичные значимые различия между группой цитиколина и плацебо $(54,8$ и $64,7 \%$ соответственно, $\mathrm{p}=0,0003)$. Эти результаты указывают на то, что применение цитиколина даже в течение первых 2 нед после развития инсульта позволяет снизить инвалидизацию и смертность на 10-12\% [43].

В настоящее время проводится многоцентровое двойное слепое плацебоконтролируемое исследование цитиколина, который применяют в первые 24 ч после развития ИИ в дозе 1 г 2 раза в сутки внутривенно с последующим приемом внутрь в течение 6 нед [44].

\section{Ал ь б у м и н}

На модели ишемии у животных было показано, что применение человеческого альбумина в высоких дозах приводит к значительному уменьшению объема инфаркта, при этом «терапевтическое окно» составляет до 4 ч [45]. Эффект альбумина связывают с его выраженными антиоксидантными свойствами, способностью поддерживать онкотическое давление, способствовать гемодилюции, а также обеспечивать нормальную проницаемость микроциркуляторного русла. Применение альбумина приводит к уменьшению отека мозга при инфаркте и улучшает перфузию ишемизированной ткани. В пилотном исследовании продемонстрирована хорошая переносимость альбумина в дозе $0,37-2,05$ г/кг у пациентов в первые 16 ч заболевания. Вероятность более благоприятного исхода была выше у больных, получавших альбумин в более высокой дозе (1,37-2,05 г/кг). В настоящее время проводится многоцентровое рандомизированное плацебоконтролируемое исследование 3-й фазы [46]. 


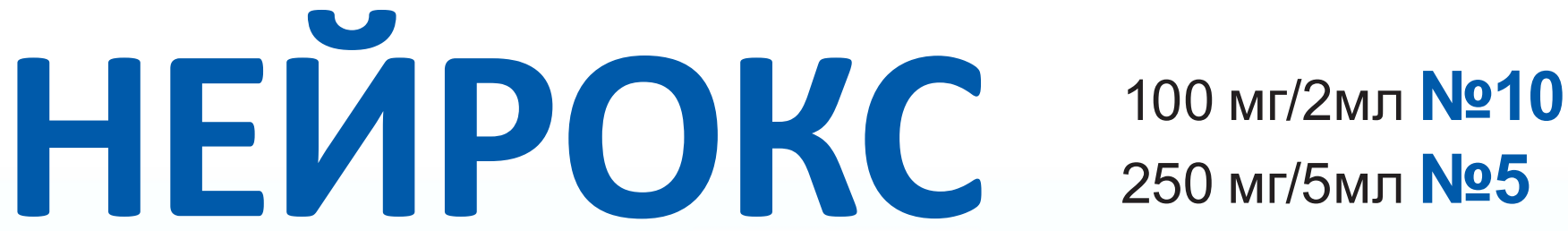

Этилметилгидроксипиридина сукцинат

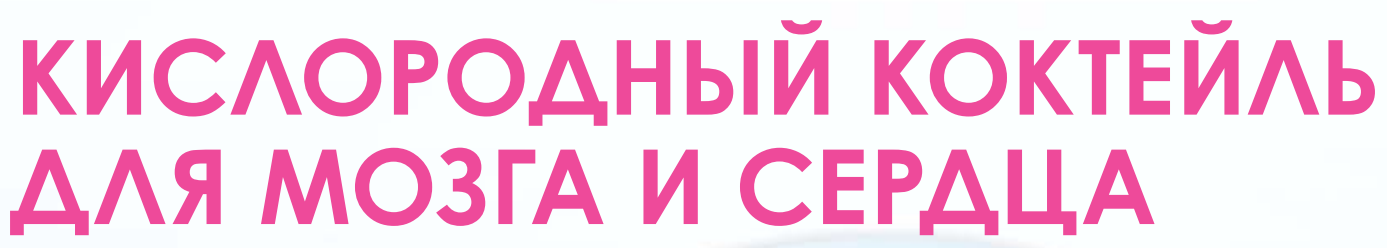

- Антиоксидант

- Антигипоксант

Утвержден в стандарт медицинской помощи больным с инсультом**

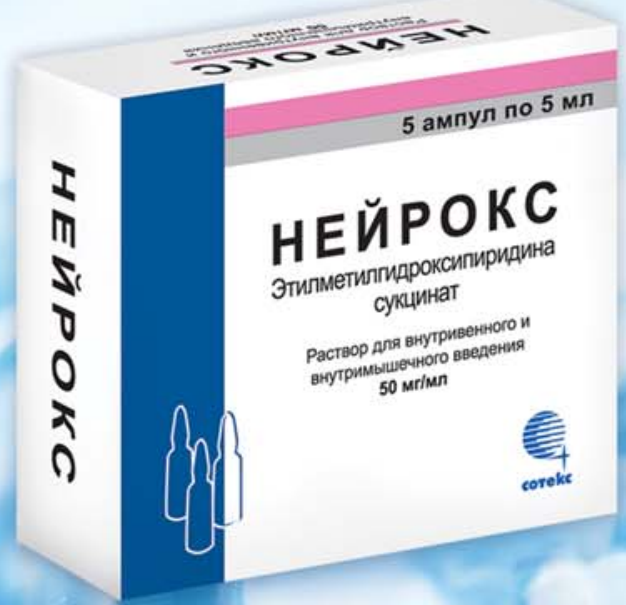

* Утвержден распоряжением Правительства РФ от 30 сентября 2009 г. №2135-р под группировочным названием этилметилгидроксипиридина сукцинат. ** Утвержден приказом Министерства здравоохранения и социального развития Российской Федерации от 1 августа 2007 г. №513 под группировочным названием этилметилгидроксипиридина сукцинат. 


\section{Стволовы е клетки}

Особое внимание в настоящее время уделяется клеточной терапии, эффект которой сопряжен не столько с воздействием на звенья ишемического каскада, сколько со стимуляцией нейропластичности (в этом плане клеточная терапия дополняет методы реабилитации). Существуют экспериментальные свидетельства того, что экзогенно введенные стволовые клетки (мезенхимальные клетки костного мозга, клетки пуповинной крови, клетки плода и стволовые клетки головного мозга) при локальном и системном применении могут попадать в ишемический очаг и стимулировать механизмы восстановления. Это действие связывается с секрецией стволовыми клетками различных факторов роста (VEGF, bFGF, BDNF и др.), которые стимулируют ангиогенез, нейрогенез и пластичность синапсов, а также со стимуляцией выработки эндогенных факторов роста [47]. К настоящему времени показано, что интрацеребральная имплантация нервных клеток у человека является доступной и безопасной [48, 49]. В небольших исследованиях была также доказана безопасность внутривенного применения аутологичных стромальных клеток костного мозга [50] и клеток пуповинной крови в подостром периоде инсульта [51].

\section{Ги п о т ер ми и}

K настоящему времени умеренная терапевтическая гипотермия имеет наиболее основательную доказательную базу среди остальных методов нейропротекции. В течение последних 20 лет было доказано, что, замедляя метаболические механизмы повреждения ткани мозга, гипотермия оказывает выраженный нейропротективный эффект. В основополагающем исследовании [18] удалось продемонстрировать, что умеренная терапевтическая гипотермия приводит к значимому уменьшению смертности и нарушений неврологических функций после остановки сердца. Хотя крупных клинических исследований терапевтической гипотермии при ИИ пока не проводилось, это один из наиболее перспективных методов нейропротекции. Несмотря на то что окно терапевтических возможностей этой методики подходит для пациентов с ИИ, ее применение сталкивается с рядом трудностей: организационные сложности, особенности ведения пациентов в состоянии гипотермии и связанные с ней нежелательные явления. В пилотных исследованиях продемонстрирована возможность применения гипотермии у пациентов в течение 12 ч после начала инсульта, длительность охлаждения составила 24 ч [52-54]. На данный момент установлено, что ключевым моментом является быстрое достижение целевой температуры $\left(<35^{\circ} \mathrm{C}\right)$, для чего используется комбинированный подход: внутривенное введение охлажденного физиологического раствора и применение эндоваскулярных охлаждающих устройств. Вторым важным фактором эффективного и безопасного охлаждения является борьба с судорогами с помощью фармакотерапии [55]. Наконец, особое значение имеет продолжительность согревания пациента [56]. В 2010 г. Всемирной организацией по изучению инсульта (WSO) предложена программа клинической разработки гипотермии при ИИ, включающая ряд исследований 2-й фазы и одно опорное исследование 3-й фазы [56, 57]. В настоящее время проводятся исследования гипотермии в комбинации с тромболитической терапией, в одном из которых уже была продемонстрирована доступность и безопасность применения в тече- ние 6 ч после начала инсульта эндоваскулярной гипотермии до $33^{\circ} \mathrm{C}$ на протяжении 24 ч с последующим согреванием в течение 12 ч [58].

Комбинированное применение

тромболизиса и н ейропротекци и

Одно из современных направлений в изучении терапии ИИ - поиск возможностей повышения эффективности тромболизиса. Логично предположить, что применение алтеплазы в комбинации с нейропротектором будет способствовать увеличению степени клинического улучшения у пациентов или диапазона «терапевтического окна» и снижению частоты геморрагических осложнений благодаря поддерживанию жизнеспособности нейронов в пенумбре [59]. В то же время существует мнение, что неэффективность изолированного применения нейропротекторов в клинических условиях обусловлена отсутствием субстрата для их приложения (т. е. жизнеспособной ткани в пенумбре) за пределами «терапевтического окна» и использования только нейропротекции без реперфузии недостаточно для достижения значимого клинического улучшения [60]. Еще один аргумент в пользу комбинированного лечения: некоторые нейропротекторы, как и реперфузионная терапия, способствуют улучшению церебрального кровотока (это касается, в частности, факторов роста и антагонистов NMDAрецепторов) [61]. Тем не менее поиски в этом направлении пока не увенчались значимым успехом. Предполагается, что тромболизис и нейропротекция обладают не столько аддитивным, сколько синергичным эффектом, доказать преимущество которого по сравнению только с тромболизисом непросто [62]. Наиболее многообещающим в этом плане выглядит уже упоминавшееся комбинированное применение гипотермии и тромболизиса. Среди фармакологических препаратов, которые в настоящее время изучаются в качестве дополнения к алтеплазе, следует отметить мочевую кислоту, однократное внутривенное применение которой в дозе 1 г в комбинации с системным тромболизисом изучается в многоцентровом исследовании 2/3-й фазы [63]. Ранее было показано, что уровень эндогенной мочевой кислоты на момент проведения тромболизиса коррелирует с благоприятным исходом лечения [64].

\section{З а к лю че н и е}

Детальное знание патофизиологии ишемического повреждения ткани головного мозга и наличие огромного количества веществ, потенциально способных повлиять на исход ишемии, пока так и не позволили создать нейропротекторные препараты, обладающие однозначно доказанной клинической эффективностью. Причинами этого являются как далекие от идеала подходы к доклиническим исследованиям веществ-кандидатов, обусловленные выраженной гетерогенностью инсульта у человека по сравнению с лабораторной моделью, так и, возможно, недостаточная обоснованность изолированного применения нейропротекторов без реперфузии. В данный момент в клинической практике обоснованным является применение безопасных препаратов, обладающих наиболее серьезной доказательной базой (например, цитиколина). Наиболее перспективными направлениями являются поиск новых фармакологических нейропротекторов, включая клеточную терапию, дальнейшее изучение и внедрение терапевтической гипотермии и исследование различных видов комбинированной нейропротективной терапии. 





1. Feigin V.L., Lawes C.M.M., Bennett D.A. et al. Worldwide stroke incidence and early case fatality reported in 56 population-based studies: a systematic review. Lancet Neurol 2009;8(4):355-69.

2. Исмагилов М.Ф., Василевская О.В., Гайфутдинов Р.Т. и др. Оценка эффективности церетона в остром периоде ишемического инсульта. Журн неврол и психиатр 2009;3:35-6.

3. Adams H.P., Jr, del Zoppo G., Alberts M.J. et al. Guidelines for the Early Management of Adults With Ischemic Stroke. Stroke 2007;38:1655-711.

4. Hacke W. Kaste M., Bluhmki E. et al. Thrombolysis with alteplase 3 to 4.5 hours after acute ischemic stroke. N Engl $\mathbf{J}$ Med 2008;359(13):1317-29.

5. Warlow C., van Gijn J., Dennis M. et al. Stroke: practical management. 3rd ed. Oxford: Blackwell Publishung, 2008;551 p.

6. The National Institute of Neurological Disorders and Stroke rt-PA Stroke Study Group. Tissue plasminogen activator for acute ischemic stroke. N Engl J Med 1995;333:1581-7.

7. Ginsberg M.D. Current Status of Neuroprotection for Cerebral Ischemia. Synoptic Overview. Stroke 2009;40:S111-S114 8. Feuerstein G.Z., Chavez J. Translational Medicine for Stroke Drug Discovery: The Pharmaceutical Industry Perspective. Stroke 2009;40:S121-S125.

9. O'Collins V.E., Macleod M.R., Donnan G.A. et al. 1026 experimental treatments in acute stroke. Ann Neurol 2006;59:467-77 10. Martinez-Vila E., Sieira P. Current status and perspectives of neuroprotection in ischemic stroke treatment. Cerebrovasc Dis

2001;11(Suppl. 1):60-70.

11. Philip M., Benatar M., Fisher M. et al. Methodological quality of animal studies of neuroprotective agents currently in phase II/III acute ischemic stroke trials. Stroke

2009;40(2):577-81.

12. Lees K.R., Zivin J.A., Ashwood T. et al. NXY-059 for acute ischemic stroke. N Engl J Med 2006;354:588-600.

13. Shuaib A., Lees K.R., Lyden P. et al. NXY059 for the treatment of acute ischemic stroke. N Engl J Med 2007;357:562-71.

14. Savitz S.I., Fisher M. Future of neuroprotection for acute stroke: in the aftermath of the SAINT trials. Ann Neurol 2007;61(5):396-402. 15. Green A.R., Odergren T, Ashwood T. Animal models of stroke: do they have value for discovering neuroprotective agents. Trends Pharmacol Sci 2003;24:402-8.

16. Stroke Therapy Academic Industry Roundtable. Recommendations for standards regarding pre-clinical neuroprotective and restorative drug development. Stroke 1999;30:2752-8.

17. Stroke Therapy Academic Industry Roundtable II. Stroke Therapy Academic Industry Roundtable II (STAIR-II). Stroke

\section{1;32:1598-606}

18. Bernard S.A., Gray T.W., Buist M.D. et al. Treatment of comatose survivors of out-of-hospital cardiac arrest with induced hypothermia. N Engl J Med 2002;346:557-63.

19. Ovbiagele B., Kidwell C.S., Starkman S.et al. Neuroprotective agents for the treatment of acute ischemic stroke. Curr Neurol Neurosci Rep 2003;3:9-20.

20. Muir K.W., Ford I., Reid J.L. et al. Magnesium for acute stroke (Intravenous Magnesium Efficacy in Stroke trial): randomised controlled trial. Lancet 2004;363:439-45. 21. Saver J.L., Eckstein M., Stratton S.J. et al. for the FAST-MAG Investigators. The Field Administration of Stroke Therapy Magnesium (FAST-MAG) Phase 3 Clinical Trial. Ongoing Clinical Trial Poster Session Abstract Book, $29^{\text {th }}$ International Stroke Conference, San Diego, CA, February 5, 2004. 22. Muller W.E., Mü ller W.E., Eckert G.P. et al. Piracetam: novelty in a unique mode of action. Pharmacopsychiatry 1999;32:2-9. 23. Winblad B. Piracetam: a review of pharmacological properties and clinical uses. CNS. Drug Rev 2005;11:169-82.

24. De Deyn P.P., Reuck J.D., Deberdt W. et al. Treatment of acute ischemic stroke with piracetam. Members of the Piracetam in Acute Stroke Study (PASS) Group. Stroke 1997;28:2347-52.

25. Луцкий М.А. Анализ эффективности мексидола в комплексном лечении больных с ишемическим инсультом. Журн неврол и психиатр 2010;57-9.

26. Румянцева С.А., Евсеев В.Н., Елисеев Е.В. Антиоксидантная терапия при остром ишемическом инсульте. Атмосфера. Нервн бол 2009;8-12.

27. Скворцова В.И., Стаховская Л.В., Нарциссов Я.Р. и др. Рандомизированное двойное слепое плацебоконтролируемое исследование эффективности и безопасности мексидола в комплексной терапии ишемического инсульта в остром периоде. Инсульт. Неврол и психиатр 2006;(прил. 18):47-54. 28. Parnetti L., Amenta F., Gallai V. Choline alphoscerate in cognitive decline and in acute cerebrovascular disease: an analysis of published clinical data. Mech Ageing Dev

2001;122(16):2041-55.

29. Barbagallo Sangiorgi G., Barbagallo M, Giordano M. et al. alpha-

Glycerophosphocholine in the mental recovery of cerebral ischemic attacks. An Italian multicenter clinical trial. Ann N Y Acad Sci 1994;717:253-69.

30. Одинак М.М., Вознюк И.А., Пирадов М.А. и др. Многоцентровое (пилотное) исследование эффективности глиатилина при остром ишемическом инсульте. Анн клин и эксперим неврол 2010;1:20-8.

31. Tatebayashi Y., Lee M.H., Li L. et al. The dentate gyrus neurogenesis: a therapeutic target for Alzheimer's disease. Acta Neuropathol
2003; 105:225-32.

32. Ren J.M., Sietsma D., Qiu S. et al Cerebrolysin enhances functional recovery following focal cerebral infarction in rats. Restor Neurol Neurosci 2007;25:25-31.

33. Haffner Z. Cerebrolysin in acute ischemic stroke. Cephalalgia Hung 1999;5:52-3.

34. Ladurner G., Kalvach P., Moessler H. et al. Neuroprotective treatment with cerebrolysin in patients with acute stroke: a randomised controlled trial. J Neural Transm 2005;112:415-28. 35. Hong Z., Moessler H., Bornstein N. et al. A double-blind, placebo-controlled, randomized trial to evaluate the safety and efficacy of Cerebrolysin in patients with acute ischaemic stroke in Asia-CASTA. Int J Stroke 2009;4(5):406-12.

36. Ziganshina L.E., Abakumova T., Kuchaeva A. Cerebrolysin for acute ischaemic stroke. Cochrane Database Syst Rev

2010(4):CD007026.

37. Heiss W.-D. Cerebrolysin in patients with acute ischemic stroke - the CASTA study. 7th World Stroke Congress, Plenary III: Large Clinical Trials Closing Session. Presented October 16, 2010.

38. Tazaki Y., Sakai F., E Otomo E. et al. Treatment of acute cerebral infarction with a choline precursor in a multicenter double-blind placebo-controlled study. Stroke

1988;19(2):211-6.

39. Clark W.M., Warach S.J., Pettigrew L.C. et al. A randomized dose-response trial of citicoline in acute ischemic stroke patients. Citicoline Stroke Study Group. Neurology 1997;49(3):671-8.

40. Clark W.M., Williams B. J., Selzer K. A. et al. A randomized efficacy trial of citicoline in patients with acute ischemic stroke. Stroke 1999;30(12):2592-7.

41. Clark W.M., Wechsler L.R., Sabounjian L.A. et al. A phase III randomized efficacy trial of $2000 \mathrm{mg}$ citicoline in acute ischemic stroke patients. Neurology 2001;57(9):1595-602. 42. Davalos A., Castillo J., Alvarez-Sabin J. et al. Oral Citicoline in Acute Ischemic Stroke: An Individual Patient Data Pooling Analysis of Clinical Trials. Stroke 2002;33:2850-7.

43. Saver J.L., Wilterdink J. Choline precursors in acute and subacute human stroke: a metaanalysis. Stroke 2002;33:353.

44. Bolland K., Whitehead J., Cobo E. et al. Evaluation of a sequential global test of improved recovery following stroke as applied to the ICTUS trial of citicoline. Pharm Stat 2009;8(2):136-49.

45. Belayev L., Liu Y., Zhao V. et al. Human albumin therapy of acute ischemic stroke: marked neuroprotective efficacy at moderate doses and with a broad therapeutic window. Stroke 2001;32:553-60.

46. Ginsberg M.D., Palesch Y.Y., Martin R.H et al. The albumin in acute stroke (ALIAS) multicenter clinical trial: safety analysis of part 1 and rationale and design of part 2. Stroke 
2011;42(1):119-27.

47. Gutierrez M., Merino J.J., de Lecinana M.A. et al. Cerebral protection, brain repair, plasticity and cell therapy in ischemic stroke. Cerebrovasc Dis 2009;27(Suppl. 1):177-86.

48. Kondziolka D., Villemagne V.L., Wechsler L. et al. Neurotransplantation for patients with subcortical motor stroke: a phase 2 randomized trial. J Neurosurg, 2005;103:38-45.

49. Kondziolka D., Wechsler L., Goldstein S. et al. Transplantation of cultured human neuronal cells for patients with stroke. Neurology 2000;55:565-9.

50. Bang O.Y., Lee J.S., Lee P.H. et al. Autologous mesenchymal stem cell transplantation in stroke patients. Ann Neurol 2005; 57:874-82.

51. Пирадов М.А., Сергеев Д.В., Танашян М.М. Применение клеток пуповинной крови в реабилитации пациентов, перенесших ишемический инсульт. В кн.: Терапевтический потенциал клеток пуповинной крови при негематологических заболеваниях. Под ред. М.А. Пальцева, В.Н. Смирнова. М.: Медицина, 2011;126-33.

52. Kammersgaard L.P., Rasmussen B. H., Jorgensen H.S. et al. Feasibility and safety of inducing modest hypothermia in awake patients with acute stroke through surface cooling: A case-control study: the Copenhagen Stroke Study. Stroke 2000;31:2251-6. 53. De Georgia M.A., Krieger D. W., AbouChebl A. et al. Cooling for Acute Ischemic Brain Damage (COOL AID): a feasibility trial of endovascular cooling. Neurology 2004;63:312-7.

54. Guluma K.Z., Hemmen T.M., Olsen S.E. et al. A trial of therapeutic hypothermia via endovascular approach in awake patients with acute ischemic stroke: methodology. Acad Emerg Med 2006;13:820-7.

55. Froehler M.T., Ovbiagele B. Therapeutic hypothermia for acute ischemic stroke. Expert Rev Cardiovasc Ther 2010;8(4):593-603. 56. Van der Worp H.B., Macleod M. R., Kollmar R. Therapeutic hypothermia for acute ischemic stroke: ready to start large randomized trials? J Cereb Blood Flow Metab 2010;30(6):1079-93.

57. Yenari M.A., Hemmen T.M. Therapeutic hypothermia for brain ischemia: where have we come and where do we go? Stroke 2010;41(Suppl. 10):S72-4.

58. Hemmen T.M., Raman R., Guluma K.Z. et al. Intravenous thrombolysis plus hypothermia for acute treatment of ischemic stroke (ICTuSL): final results. Stroke 2010;41(10):2265-70.

59. Donnan G.A., Davis S.M. Parsons M.W. et al. How to make better use of thrombolytic therapy in acute ischemic stroke. Nat Rev Neurol 2011;7(7):400-9.

60. Chavez J.C., Hurko O., Barone F.C. et al. Pharmacologic interventions for stroke: looking beyond the thrombolysis time window into the penumbra with biomarkers, not a stopwatch. Stroke 2009;40(10): e558-e563.

61. Sutherland B.A., Papadakis M., Chen R.-L. et al. Cerebral blood flow alteration in neuroprotection following cerebral ischaemia. J Physiol 2011;589(Pt 17):4105-14.

62. Lu M. Assessing combination treatments in acute stroke: preclinical experiences. Behav Brain Res 2005;162(2): 165-72.

63. Amaro S., Canovas D., Castellanos M. et al. The URICO-ICTUS study, a phase 3 study of combined treatment with uric acid and rtPA administered intravenously in acute ischaemic stroke patients within the first $4.5 \mathrm{~h}$ of onset of symptoms. Int J Stroke 2010;5(4):325-8. 64. Logallo N., Naess H., Idicula T.T. et al. Serum uric acid: neuroprotection in thrombolysis. The Bergen NORSTROKE study. BMC Neurol 2011;11:114.

\section{Н.В. Вахнина}

\section{Современная терапия когнитивных нарушений}

Когнитивные расстройства (КР) являются весьма распространенным видом неврологических нарушений особенно у пожилых пациентов. Выбор терапевтической стратегии при КР определяется как этиологией нарушений, так и их выраженностью. В лечении легких и умеренных КР основное значение имеют мероприятия, направленные на профилактику прогрессирования КР и предотвращение деменции: адекватное лечение имеющихся сердечно-сосудистых заболеваний, профилактика острых нарушений мозгового кровообращения, рациональное питание, умеренные физические и интеллектуальные упражнения, борьба с избыточной массой тела и гиподинамией. По данным ряда исследований, указанные меры уменьшают риск развития деменции, в том числе у лии, с генетической предрасположенностью. Фармакотерапия легких и умеренных КР обычно включает вазоактивные, нейрометаболические и норадренергические препараты. Тяжелые КР являются показанием для назначения меманти-

на и/или ацетилхолинергических препаратов, т. е. базисной терапии наиболее распространенных форм деменции (болезни

Альигеймера, деменции с тельцами Леви, сосудистой и смешанной деменции). Длительное использование мемантина и/или ацетилхолинергических препаратов уменьшает выраженность когнитивных и поведенческих симптомов деменции, повышает самостоятельность пациентов, продлевает время активной жизни.

Ключевые слова: когнитивные нарушения, лечение деменции. Контакты: Наталья Васильевна Вахнина nvakhnina71@таil.ru

\section{Current therapy for cognitive impairments N.V. Vakhnina \\ Department of Nervous Diseases, I.M. Sechenov First Moscow State Medical University}

Cognitive impairments (CIS) are a highly common type of neurological disorders particularly in elderly patients. Choice of a therapeutic strategy for CI is determined by the etiology of abnormalities and their degree. Measures to prevent CI progression and dementia: adequate treatment of existing cardiovascular diseases, prevention of stroke, balanced nutrition, moderate physical and intellectual exercises, and combatting overweight and low activity are of basic value in treating mild and moderate CIs. According to the data of a number of investigations, the above measures reduce the risk of dementia, including in the genetically predisposed. Pharmacotherapy for mild and moderate

CIs generally comprises vasoactive, neurometabolic, and noradrenergic agents. The indication for the use of memantine and/or acetyl- 